\title{
A teoria e a prática da interdisciplinaridade em Ciência da Informação
}

\section{Lucinéia Bicalho}

\begin{abstract}
Mestre e Doutora em Ciência da Informação; PósGraduanda em Gestão do Patrimônio Histórico e Cultural; pesquisadora da temática Fundamentos teóricos da Ciência da Informação; Assessora de Informação da Faculdade de Letras/UFMG
\end{abstract}

Marlene de Oliveira

Professora Associada II da Escola de Ciência da Informação da UFMG. Atua no PPGCI e pesquisa as temáticas: Fundamentos teóricos da Ciência da Informação e Biblioteconomia -CIB, Comunicação Científica com uso de técnicas bibliométricas

A produção do conhecimento científico tem sido realizada por meio de experiências que privilegiam a contribuição de saberes, provenientes de diferentes áreas. O presente artigo tem como finalidade apresentar as principais modalidades de interação que ocorrem na prática da pesquisa científica - multidisciplinaridade, interdisciplinaridade e transdisciplinaridade -, tendo, como referência, a literatura produzida no âmbito da ciência da informação. Pesquisadores contemporâneos de outras áreas contribuem para embasar essas teorias, cuja evolução provocou grandes mudanças nos significados desses termos. A pesquisa completa, da qual este artigo é parte, analisou a produção científica da ciência da informação no Brasil, traçando um perfil da pesquisa na área, relativamente à utilização dessas abordagens, concluindo-se que diferentes formas e níveis de interações são encontrados nas pesquisas desenvolvidas na Ciência da Informação, sendo a multidisciplinaridade a mais comum. Conclui-se, ainda, que a situação terminológica atual requer uma atualização desses conceitos, principalmente no âmbito da Ciência da Informação, para uma maior conscientização das implicações de ser uma ciência contemporânea, que se reconhece interdisciplinar. 
Palavras-chave: Multidisciplinaridade;

Interdisciplinaridade; Transdisciplinaridade; Ciência da Informação; Terminologia.

\section{The theory and practice of interdisciplinarity in Information Science}

The production of scientific knowledge has been carried through experiences that emphasize the contribution of knowledge from different areas. This article aims to present the main modalities of interaction that occur in the practice of scientific research - multidisciplinarity, interdisciplinarity and transdisciplinarity - having as reference the literature produced in the scope of information science. Contemporary researchers from other fields contribute to the basement of these theories, whose development has caused major changes in the meanings of these terms. The complete investigation, of which this article is part, examined the scientific production of information science in Brazil, tracing a profile of research in the area regarding the use of these approaches, concluding itself that different forms and levels of interactions are found in his research Information Science, being multidisciplinarity the most common. It concludes also that the terminological current situation requires an update of these concepts, mainly in the context of information science, to a greater awareness of the implications of being a contemporary science recognized as interdisciplinar.

Keywords: Multidisciplinary; Interdisciplinary; Transdisciplinary; Information Science; Terminology.

Recebido em20.03.2011 Aceito em 30.07.2011

\section{Introdução}

Para o desenvolvimento das ciências, tornou-se imprescindível utilizar abordagens e metodologias que possibilitem alcançar resultados decorrentes da participação de várias disciplinas, em diferentes níveis e formatos. Algumas ciências, surgidas no pós Segunda Guerra, possuem traços que as diferenciam da ciência chamada clássica ou moderna. A conformação da ciência contemporânea é, pois, em grande medida, 
resultado de inúmeras e diversificadas formas de interação entre saberes, que fazem dela um complexo sistema de relações disciplinares.

Essas interações têm sido estudadas e categorizadas por autores de diversas áreas, em função da importância e da diversidade em que ocorrem, com especial atenção aos muitos significados e tentativas de subdivisões dos termos que denominam as principais modalidades encontradas. Uma dessas características, especialmente importante para a Ciência da Informação, é a interdisciplinaridade, associada à área desde sua origem, tornando-se uma marca de sua evolução e amplamente reconhecida por sua comunidade.

Este artigo, parte de pesquisa desenvolvida em nível de doutoramento ${ }^{1}$, apresenta a evolução conceitual dos termos relacionados a três abordagens que envolvem interações entre disciplinas: multidisciplinaridade, interdisciplinaridade e transdisciplinaridade, com ênfase nas ideias presentes na literatura da Ciência da Informação. Pesquisadores contemporâneos de outras áreas também fazem parte da apresentação das citadas modalidades de pesquisa, contribuindo para embasar as reflexões dos estudiosos da CI.

\section{As interações entre disciplinas científicas}

As abordagens multi, inter e transdisciplinar parecem indicar novos e adequados caminhos para fazer avançar o conhecimento científico de forma inovadora, possibilitando à CI e a tantas outras disciplinas fortalecer seus fundamentos disciplinares e, ao mesmo tempo, caminhar no compasso do paradigma científico que se delineia neste século XXI.

Os conceitos associados aos três termos aqui mencionados, entretanto, foram assumindo significações diversas ao longo das últimas décadas, mantendo, contudo, a ideia comum de que representam movimentos que surgiram em resposta à fragmentação do conhecimento. Aspectos básicos, apresentados a seguir, identificam cada uma das três abordagens, que são classificadas sob diferentes perspectivas e apresentam diferentes níveis de integração entre disciplinas. Elas partem de algo que seria colocado junto com uma coordenação paralela de pontos de vista, no caso da multidisciplinaridade, passando a uma dimensão que ultrapassa a anterior e avança para uma combinação, convergência ou complementaridade, no terreno intermediário da interdisciplinaridade, e alcançam algo próximo à fusão ou unificação, enfim, a transdisciplinaridade (POMBO, 2004).

A concepção de cada uma dessas abordagens tem como ponto de partida a ideia da disciplinaridade. Para Morin (2002), na acepção em que se relaciona ao conhecimento acadêmico-científico, o termo disciplina

${ }^{1}$ BICALHO, L. M. As relações interdisciplinares refletidas na literatura brasileira da Ciência da Informação. Belo Horizonte: UFMG, 2009. 267f. Tese (Doutorado em Ciência da Informação) - Programa de Pós-Graduação em Ciência da Informação, Escola de Ciência da Informação, Universidade Federal de Minas Gerais, Belo Horizonte, 2009. 
culminou com o surgimento de vários ramos ou especializações no âmbito da ciência, no século XIX e, ao longo do século $X X$, se desenvolveu mais ainda, graças ao progresso da pesquisa científica. A natureza de uma disciplina pode ser caracterizada, segundo alguns critérios identificados por Heckhausen (2006), que, em muitos casos, não podem ser muito bem delimitados ou observados. São eles:

a) domínio material - conjunto dos objetos dos quais se ocupam. Muitas disciplinas se sobrepõem neste domínio;

b) domínio de estudo - ângulo específico de seu domínio material. Noção vagamente definida que depende da constituição de uma dada disciplina;

c) nível de integração teórica - construção da "realidade" de seus domínios em termos teóricos, ou seja, seus conceitos fundamentais e unificadores devem ser abrangentes, o suficiente para explicar e prever os fenômenos de seu domínio de estudo. Define a maturidade da disciplina e é o critério mais importante de identificação de uma disciplina;

d) métodos próprios - para apreender e transformar os fenômenos. Uma disciplina se torna autônoma quando aperfeiçoou seus próprios métodos, que devem ser adaptados à natureza do domínio de estudo, com correspondência entre aplicação concreta dos métodos e as leis gerais no plano teórico;

e) instrumentos de análise - apoiam-se em estratégia lógica, nos raciocínios matemáticos e na construção de modelos de processos. Aplicam-se a diversos domínios e são critérios neutros;

f) aplicações - orientação para a aplicação e a utilização prática no campo de atividade profissional;

g) contingências históricas - momento por que passa a disciplina em seu processo de evolução histórica, no qual interfere tanto a lógica interna do domínio de estudo quanto forças exteriores (HECKHAUSEN, 2006).

A principal característica das relações em que ocorre a abordagem chamada multidisciplinaridade ${ }^{2}$ é a justaposição de ideias; não há integração entre as disciplinas. A multidisciplinaridade estaria hierarquicamente no primeiro nível, inferior, de integração entre as disciplinas, quando comparada à inter e à transdisciplinaridade.

Em definição de Nicolescu (2000), a multidisciplinaridade corresponde à busca da integração de conhecimentos, por meio do estudo de um objeto de uma mesma e única disciplina, por várias delas ao mesmo tempo. Este tipo de pesquisa traz contribuições significativas a uma disciplina específica, porque "ultrapassa as disciplinas, mas sua finalidade continua inscrita na estrutura da pesquisa disciplinar" (NICOLESCU, 2000. p. 14). Para Dellatre (2006) (que considera apenas os termos pluri e interdisciplinar), a pluridisciplinaridade pode ser entendida como:

\footnotetext{
${ }^{2}$ Aqui, o termo é equivalente à pluridisciplinaridade, a exemplo do que fazem outros autores, como Gusdorf (1990), Pombo (1994) e Nicolescu et al. (2000).
} 
uma simples associação de disciplinas que concorrem para uma realização comum, mas sem que cada disciplina tenha que modificar significativamente a sua própria visão das coisas e dos próprios métodos [...]. Toda realização teórica que põe em prática saberes diversos corresponde de fato a um empreendimento pluridisciplinar (DELATTRE, 2006, p. 280).

A interdisciplinaridade ocupa posição intermediária entre a multi e a transdisciplinaridade, com a ocorrência de intercâmbios e enriquecimentos mútuos entre as disciplinas. Cada qual aceita esforçar-se fora do seu domínio próprio e da sua própria linguagem técnica, para aventurar-se em um domínio de que não é o proprietário exclusivo. "A interdisciplinaridade supõe abertura de pensamento, curiosidade que se busca além de si mesmo" (GUSDORF, 1990 apud POMBO, 1994, p. 2).

Em 1972, três definições para o termo são apresentadas por Jean Piaget, Erich Jantsch e André Lichnerowicz, dando início a uma ampla discussão. A interdisciplinaridade, para Jantsch, seria:

Uma axiomática comum a um grupo de disciplinas conexas e definida no nível hierárquico imediatamente superior à pluridisciplinaridade, com objetivos múltiplos e uma coordenação procedendo do nível superior (JANTSCH, 1972 apud JAPIASSU, 1976, p. 73).

Berger diz que a interdisciplinaridade é a interação entre duas ou mais disciplinas e que um grupo interdisciplinar compõe-se de pessoas que receberam formação nos diferentes domínios do conhecimento (disciplinas), tendo, cada um, conceitos, métodos, dados e temas próprios (BERGER, 1972 apud POMBO, 1994, p. 2).

Jean Piaget realça importante aspecto da interdisciplinaridade, quando diz que nela ocorrem cooperação $e$ intercâmbios reais $e$, consequentemente, enriquecimentos mútuos (PIAGET, 1972 apud POMBO, 1994).

A ambição da interdisciplinaridade é diferente daquela da multidisciplinaridade, afirma Nicolescu (2000). Ela...

[...] diz respeito à transferência de métodos de uma disciplina para outra", podendo ocorrer em três graus: de aplicação (como na transferência de métodos da física nuclear para a medicina); epistemológico (a exemplo da transferência de métodos da lógica formal para o campo do direito); e de geração de novas disciplinas (como na transferência de métodos da matemática para a física, gerando a física matemática) (NICOLESCU, 2000, p.15).

No Brasil, Japiassu e Marcondes (1991) definem interdisciplinaridade como um método de pesquisa capaz de promover a interação entre duas ou mais disciplinas. Esta interação, segundo os autores, pode ir "da simples comunicação das ideias até a integração mútua dos conceitos, da 
epistemologia, da terminologia, da metodologia, dos procedimentos, dos dados e da organização da pesquisa" (JAPIASSU; MARCONDES, 1991.

A partir de muitos estudos realizados, várias taxonomias e propostas de classificação para a atividade interdisciplinar têm sido apresentadas por pesquisadores de várias áreas no intuito de compreender como se dá a prática interdisciplinar, de acordo com princípios epistemológicos que julgam mais convenientes ao entendimento do assunto, dos quais citamos: Heinz Heckhausen (1972; 2006), Boisot (1972); Japiassu (1976); Huerkamp et al. (1978); Klein (1990); Pombo (1994); e Leonoir (2003).

O terceiro nível de integração entre disciplinas - a transdisciplinaridade -, como também a multi e a interdisciplinaridade, não nega as disciplinas, uma vez que se ancora nelas para o seu desenvolvimento. O mais importante é considerar a unidade do saber, algo que, segundo Gusdorf (2006), somente é encontrado no verdadeiro cientista, o qual, diferentemente do especialista, "ao mesmo tempo que aprofunda a inteligibilidade deste ou daquele domínio do conhecimento, é capaz de situar o seu saber na totalidade do saber, isto é, no horizonte global da realidade humana" (GUSDORF, 2006, p. 56).

A transdisciplinaridade ainda está em construção, sendo discutida e debatida em larga escala atualmente, assim como nos primeiros eventos, ocorridos na década de 1970, na Europa, quando foram feitas as primeiras alusões ao termo ${ }^{3}$. Segundo Nicolescu (2007), Piaget descrevera, naquela ocasião, a transdisciplinaridade como "uma etapa superior das relações interdisciplinares [...] que não estará limitada ao alcance de interações ou reciprocidades entre pesquisas especializadas, mas que situará estas ligações no interior de um sistema total, sem fronteiras estáveis entre as disciplinas" (NICOLESCU, 2007, p. 1). Jantsch, segundo Pombo (1994) disse que a transdisciplinaridade seria o "último grau da coordenação susceptível de existir num sistema de educação e inovação [...] uma etapa avançada relativamente à interdisciplinaridade" (POMBO, 1994, p. 13). No modelo de Jantsch, "as ligações promovidas pela interdisciplinaridade levam as disciplinas científicas a mudarem seus conceitos e estruturas, enquanto se movem em direção a um nível mais alto de coordenação baseado em axiomas de um ponto de vista comum ou propósito focado na ação humana", sendo, portanto, "a interconexão de todos os aspectos da realidade, transcendendo a dinâmica de uma síntese dialética para alcançar a dinâmica total da realidade como um todo" (KLEIN, 1990, p. 66). Jantsch afirmou, por ocasião do evento, ser essa visão a ideal, apesar de admitir que estivesse além do completo alcance da ciência, embora, por outro lado, acreditasse que esse conceito poderia guiar a ciência em seus desenvolvimentos (KLEIN, 1990). Lichnerowicz descreveu a transdisciplinaridade como "a homogeneidade da atividade teórica em diferentes ciências e técnicas, independentemente

3 Durante o I Seminário Internacional sobre a Pluridisciplinaridade e a Interdisciplinaridade (Nice/França), 1970. 
do campo onde a atividade é efetuada", considerando a linguagem matemática como base da formulação dessa atividade (NICOLESCU, 2007, p. 2). Piaget e Lichnerowics focalizaram seus conceitos nas dinâmicas internas das ciências e em suas interações, considerando que a transdisciplinaridade forneceria um quadro conceitual que atravessaria as disciplinas. Jantsch focalizou seus objetivos externos, propondo um modelo mais amplo, envolvendo as interações com o humano e com o social, para além do sistema científico, abarcando, também, o sistema educacional e de inovação (KLEIN, 2002 apud SOMMERMAN, 2006).

Em nível internacional, o termo transdisciplinaridade surgiu, de forma explícita, na Declaração de Veneza ${ }^{4}$, documento final do colóquio intitulado A ciência diante das fronteiras do conhecimento, organizado pela UNESCO e realizado em Veneza, em 1986 (SOMMERMAN, 2005). A Carta da Transdisciplinaridade ${ }^{5}$ (2001) destaca os seguintes pontos básicos da transdisciplinaridade:

a) realidade é composta de diferentes níveis (art. 2);

b) a transdisciplinaridade é complementar à aproximação disciplinar e oferece-nos uma nova visão da natureza e da realidade (art. 3);

c) a sustentação da transdisciplinaridade reside na unificação semântica e operativa das acepções através e além das disciplinas; o formalismo excessivo, a rigidez das definições e o absolutismo da objetividade, comportando a exclusão do sujeito, levam ao empobrecimento (art. 4);

d) a visão da transdisciplinaridade é aberta, ultrapassando o domínio das ciências exatas e dialogando com as ciências humanas, a arte, a literatura, a poesia e a experiência espiritual (art.5), devendo ter uma atitude aberta também em relação a mitos e religiões (art. 9), por ser um movimento transcultural (art. 10);

e) todo habitante da terra é um ser transnacional (art. 8);

f) a educação deve ensinar a contextualizar, a concretizar e a globalizar, além da parte relativa à abstração no conhecimento; e

g) são características fundamentais da visão e da atitude transdisciplinares: o rigor, a abertura e a tolerância. O rigor na argumentação, que leva em conta todos os dados, é a melhor barreira contra possíveis desvios. A abertura comporta a aceitação do desconhecido, do inesperado e do imprevisível. A tolerância é o reconhecimento do direito às ideias e verdades contrárias às nossas (art. 14).

\footnotetext{
${ }^{4}$ Documento final do colóquio A ciência diante das fronteiras do conhecimento, organizado pela UNESCO, em Veneza, em 1986. Acesso: <http://www.cetrans.com.br/internaCetrans50b2.html?iPageId=117>. Acesso em: 17 maio 2009.

${ }^{5}$ Documento final do I Congresso Mundial da Transdisciplinaridade, organizado por UNESCO/CIRET/França, em Portugal, em 1994. Acesso: <http://www.cetrans.com.br/internaCetransd8a3.html?iPageId=115>. Acesso em: 17 maio 2009.
} 
O II Congresso Mundial da Transdisciplinaridade, realizado no Brasil, em 2005, propõe o aprofundamento teórico e prático dos três eixos, sobre os quais foi estruturada a "Mensagem"6 final do evento, quais sejam:

1) atitude transdisciplinar: Busca da compreensão da complexidade do universo e das relações humanas entre si e com a realidade e o real, através da articulação dos saberes das ciências, das artes, da filosofia, das tradições sapienciais e da experiência;

2) pesquisa transdisciplinar. Integração de processos dialéticos e dialógicos que emergem da pesquisa e mantém o conhecimento como sistema aberto, através de uma pluralidade epistemológica; e

3) ação transdisciplinar: Visa à paz e à colaboração entre as pessoas e entre as culturas, mas sem desconsiderar os contraditórios e a valorização de sua expressão, através da mediação dos conflitos oriundos do contexto local e global.

Algumas teorias estão diretamente relacionadas à abordagem transdisciplinar $^{7}$ e serão aqui abordadas, de forma resumida, uma vez que cada uma merece aprofundados estudos. Os pilares da transdisciplinaridade são, para Basarab Nicolescu: a complexidade, os níveis de realidade e a lógica do terceiro incluído. Esse autor afirma que há mútua dependência entre transdisciplinaridade e complexidade, embora alguns estudiosos ainda procurem mostrar a "supremacia" de um dos dois termos (NICOLESCU, 2000).

A complexidade seria, ao pé da letra, aquilo que é tecido em conjunto (complexus) ou "o tecido de acontecimentos, ações, interações, retroações, determinações, acasos, que constituem o nosso mundo fenomenal" (MORIN, 2003, p.20). A complexidade não se traduz apenas em quantidades de unidades e interações, é muito mais uma noção lógica do que uma noção quantitativa (MORIN, 2000; 2003). A complexidade não recusa a clareza, a ordem e o determinismo, mas os considera insuficientes para lidar com a descoberta, o conhecimento e a ação. Não se trata de um retorno ao pensamento simples para controlar e dominar o real, mas de exercer um pensamento que possa dialogar e negociar com ele (MORIN, 2000). A complexidade não tem metodologia, mas pode ter seu método, que tem por fundamento incitar o pensamento sobre conceitos, sem dá-los por concluídos, para quebrar as esferas fechadas, restabelecer articulações entre o que foi separado e não esquecer as totalidades integradoras. A complexidade atrai a estratégia, como única forma de avançar no incerto e no aleatório (MORIN, 2007). Segundo Morin (2003), na base do pensamento complexo, por sua vez, encontra-se três teorias surgidas nos anos 40, que deram origem às ciências contemporâneas: a teoria dos sistemas, a teoria da informação e a cibernética.

\footnotetext{
${ }^{6}$ Mensagem de Vitória/Vila Velha. Disponível em <http://www.redebrasileiradetransdisciplinaridade.net $>$. Acesso em: 17 maio 2009.

7 Embora estejam localizadas aqui, nesta seção sobre transdisciplinaridade, muitas dessas teorias estão também diretamente relacionadas à abordagem interdisciplinar.
} 
De acordo com o segundo pilar da transdisciplinaridade - os níveis de realidade -, a realidade transdisciplinar é estruturada em muitos níveis, substituindo aquela realidade do pensamento clássico que se resume a um único nível, unidimensional. Na pesquisa disciplinar, leva-se em conta somente um único e mesmo nível de realidade ${ }^{8}$ ou, na maioria dos casos, fragmentos deste nível (NICOLESCU, 2000). A transdisciplinaridade, por outro lado, se interessa pela "dinâmica gerada pela ação de vários níveis de realidade ao mesmo tempo" (NICOLESCU, 2000 , p. 16). Um nível de realidade é entendido como "um conjunto de sistemas invariável sob a ação de um número de leis gerais"; por exemplo, as entidades quânticas submetidas às leis quânticas, as quais estão radicalmente separadas das leis do mundo macrofísico (NICOLESCU, 2000, p. 22).

A lógica do terceiro incluído, terceiro pilar da transdisciplinaridade, cuja teoria foi formulada inicialmente por Stéphane Lupasco, tem origem na física e na filosofia, na subárea da lógica (NICOLESCU, 2001). A descoberta dos diferentes níveis de realidade mostrou que as escalas subatômicas e as supra-atômicas coexistem e são regidas por leis diferentes, tornando possível, assim, a coexistência de pares de contraditórios mutuamente exclusivos, o que rompeu com a lógica clássica, baseada nos axiomas identitários de Aristóteles $^{9}$ (rejeição da contradição) que asseguravam a validade formal das verdades teóricas (NICOLESCU, 2001; SOMMERMAN, 2005). O desenvolvimento da física quântica e a coexistência dos dois níveis de realidade (quântico e macrofísico) no plano da teoria e da experiência científica levaram "ao aparecimento de pares de contraditórios mutuamente exclusivos "A e não$A^{\prime \prime}$ : onda e corpúsculo, continuidade e descontinuidade, separabilidade $e$ não-separabilidade, causalidade local e causalidade global, etc." (NICOLESCU, 2000, p. 25-26), que contradizem a lógica clássica.

A partir das muitas ideias envolvendo 0 conceito de transdisciplinaridade, várias definições foram elaboradas, na tentativa de abarcar todo o seu significado. Domingues et al. (2001) afirmam que, além dos sentidos apontados na primeira definição que remetem "para além", "passagem", "transição", "mudança", "transformação", etc., o termo também refere-se a:

aquelas situações do conhecimento que conduzem à transmutação ou ao traspassamento das disciplinas, à custa de suas aproximações e frequentações. Pois, além de sugerir a ideia de movimento, da frequentação das disciplinas e da quebra de barreiras, a transdisciplinaridade permite pensar o cruzamento de especialidades, o trabalho nas interfaces, a

\footnotetext{
${ }^{8}$ Entende-se por realidade, "aquilo que resiste a nossas experiências, representações, descrições, imagens ou formalizações matemáticas" (NICOLESCU, 2000, p. 21).

${ }^{9}$ Os axiomas de identidade, de não contradição ou terceiro excluído, escritos na forma de proposições são: 1 ) Identidade: $A$ é $A$; 2) Não-contradição: $A$ é não-A; 3) Terceiro excluído: não há um terceiro termo T que seja, ao mesmo tempo, $A$ e não-A.
} 
superação das fronteiras, a migração de um conceito de um campo de saber para outro, além da própria unificação do conhecimento (DOMINGUES et al., 2001, p.18).

Uma grande variedade de significados é atribuída ao termo, em função das circunstâncias e contextos em que é empregado. O foco desta pesquisa está em seu aspecto científico.

Outra questão importante da abordagem transdisciplinar se concentra em sua vertente metodológica. A prática da transdisciplinaridade significa "a encarnação em cada ação, da metodologia transdisciplinar, através de um conjunto de métodos adaptados a cada situação específica", de acordo com Nicolescu (2000, p. 129). Em outras palavras, uma metodologia geral da transdisciplinaridade não existe, mas sim, "uma que se encontra a partir do problema transdisciplinar colocado" (BRANDÃO, 2007, p. 337). Em vista de um problema e um contexto específicos, esses são tratados com os materiais disponíveis, voltados para a resolução do problema e dos saberes em pauta, constituindo uma rede que se adequa ao objeto e não à solução de qualquer problema, explica o referido autor.

Reafirma-se, aqui, que as diferentes abordagens do conhecimento científico - disciplinar, interdisciplinar, multidisciplinar e transdisciplinar não são consideradas antagônicas ou excludentes, mas necessárias e, muitas vezes, complementares em diferentes etapas do processo investigativo.

Uma breve descrição da metodologia utilizada no desenvolvimento da pesquisa serve como um guia para os resultados apresentados em seguida.

\section{Metodologia}

A pesquisa da qual este artigo faz parte, teve como finalidade aprofundar os estudos sobre a área da ciência da informação, focalizando, especialmente, sua natureza interdisciplinar, através de pesquisa teórica e por meio da análise de sua práxis científica, representada em sua produção brasileira. Para dar sustentação ao estudo, a pesquisa bibliográfica buscou caracterizar as principais formas de interação ocorridas, bem como as tendências da pesquisa científica, relativamente a este aspecto. Também procurou contextualizar a área da ciência da informação, no âmbito da ciência contemporânea, por meio do estudo de suas principais características, principalmente no que se refere às mudanças de pressupostos relativos aos fundamentos que edificaram a ciência clássica ou moderna, como forma de compreender as principais características de novas ciências surgidas em meados do Sec. XX, como a ciência da informação.

A pesquisa utilizou como fonte de informações quatro periódicos científicos nacionais da área da ciência da informação, ligados a programas de pós-graduação de instituições de ensino superior. Para 
tanto, foram analisados artigos científicos publicados nesses periódicos, no período de 2001 a 2006. Foram selecionados e analisados 531 artigos científicos, dos quais foram selecionados e estudados em profundidade 158, que apresentaram propriedades indicativas de interação com outras áreas do conhecimento para o seu desenvolvimento. As análises de assunto e de conteúdo foram os principais procedimentos adotados para o estudo dos artigos, embora métodos quantitativos também tenham sido utilizados, tais como a número de autores, bem como área de formação e de atuação dos mesmos.

Os estudos teóricos desenvolvidos no âmbito da Ciência da Informação sobre as abordagens "interdisciplinares" fizeram parte da investigação de maneira destacada, como forma de melhor compreender o pensamento da área sobre o assunto.

\section{A interdisciplinaridade a partir da Ciência da Informação}

A Ciência da Informação (CI) encontrou em sua natureza interdisciplinar uma maneira de desenvolver-se. Assim, tem avançado rumo à sua emancipação, por meio de duas vertentes aparentemente conflituosas, a necessidade de fortalecer sua base teórica e, ao mesmo tempo, de interagir com outras áreas. Esse desenvolvimento ocorre sob forte influência das inúmeras e novas ferramentas tecnológicas de informação e comunicação, e deve cumprir, ao final, o seu papel de ciência social, que aplica os conhecimentos que produz em contextos sociais, culturais, econômicos e políticos.

O termo interdisciplinaridade tem sido lugar comum quando associado à ciência da informação, mas, na sua literatura, não está devidamente colocado o que isto significa, enquanto característica marcante e identitária. Na produção brasileira e do exterior, há inúmeras referências à interdisciplinaridade, como uma das características mais evidentes da área, como em Taylor (1966), Borko (1968), Merta (1969), Mikhailov; Chernyi; Gilyarevskyi (1969), Saracevic (1992), Le Coadic (1996), Dias (2000), Pinheiro (1997; 1998; 1999; 2006), Oliveira (1998; 2001), Orrico (1999), Smith (1992), Gomes (2001), Gonzalez de Gómez (2001) e Smit; Tálamo; Kobashi (2004), entre muitos outros, dos quais algumas ideias são aqui retomadas.

A natureza interdisciplinar da CI teve início, segundo Saracevic (1992) e Wersig e Nevelling (1975 apud FREIRE, 2003), em sua gênese, uma vez que se constituiu por meio da contribuição de pesquisadores oriundos de muitas disciplinas diferentes e com diferentes formações. "Entre os pioneiros havia engenheiros, bibliotecários, químicos, linguistas, filósofos, psicólogos, matemáticos, cientistas da computação, homens de negócios e outros, vindos de diferentes profissões ou ciências", diz Saracevic (1992, p. 12). O nível de contribuição de cada disciplina não foi igualmente relevante, mas essa diversidade de experiências gerou e 
sustentou a tônica interdisciplinar da ciência da informação, segundo o autor. Sua emergência foi causada, também, por interesses diferentes, devido a áreas diferentes de aplicação envolvidas no trabalho de informação (WERSIG; NEVELLING, 1975 apud FREIRE, 2003).

Uma das ocasiões em que a interdisciplinaridade na área da $\mathrm{CI}$, foi profundamente discutida (embora com ênfase no ensino), aconteceu durante a conferência internacional realizada na Universidade de Tampere/Finlândia, em 1990, cujos anais foram publicados em 1992. O evento teve como objetivo "clarificar as concepções do objeto de pesquisa, escopo e fenômeno central da ciência da informação e da biblioteconomia". Desse evento resultaram grandes contribuições sob as perspectivas histórica, empírica e teórica, conforme proposta do evento. Foram levantadas questões a respeito da natureza da $\mathrm{CI}$, seus métodos científicos, o objeto da área, sua cientificidade, seus paradigmas e o impacto da informação (VAKKARI, 1992). Na época, explica esse autor, uma nova onda de discussão relativa à natureza da CI estava em desenvolvimento, gerando a necessidade de refletir sobre a qualidade da pesquisa universitária e sobre as relações da área com outras disciplinas. Os anais do referido evento, que ainda são referência na área sobre as questões discutidas, incluem artigos de importantes pesquisadores, como Blaise Cronin, Pertti Vakkari, Tefko Saracevic, Linda Smith, Ivar Hoel, Rafael Capurro, David Ellis, Gernot Wersig e Peter Ingwesen, entre outros.

O processo evolutivo da CI, em relação aos principais estudos teóricos realizados sobre interdisciplinaridade, foi descrito por Pinheiro $(1997 ; 2005 ; 2006)$ em três fases. A primeira fase - conceitual e de reconhecimento interdisciplinar (de 1961/62 a 1969) - dá ênfase à natureza disciplinar da área e são discutidas as denominações iniciais, a confusão terminológica com a Informática, suas origens e interfaces, principalmente com a documentação, a biblioteconomia e a informática. Foi observada, também, a preocupação quanto à cientificidade da área que estava surgindo. A segunda fase - de delimitação do terreno epistemológico: princípios, metodologia e teorias próprios e influência de novas tecnologias (1970-1989) - é o período em que são estudados, com maior profundidade, o objeto e a natureza da CI, a presença da tecnologia no processo da área e o contexto de desenvolvimento científico daquele momento. A terceira fase - de consolidação da denominação e de alguns princípios, métodos, teorias e aprofundamento da discussão sobre interdisciplinaridade com outras áreas (a partir de 1991) - teve como temas aspectos relativos à organização interna da área e sua institucionalização cognitiva.

O reconhecimento, quase unânime, do caráter interdisciplinar da área da CI ou de seu objeto de estudos, é repetido de várias maneiras. Como muitos outros pesquisadores, Freire (2003) cita diretamente a expressão usada por Saracevic (1995), em que dizia que a interdisciplinaridade da CI "[...] não precisa ser procurada, está lá, no 
âmago do próprio campo científico". A CI é "uma área do conhecimento tipicamente interdisciplinar", afirmam Dumond e Bruno (2003, p. 32). Gomes (2001, p. 5) diz que não é necessário refletir sobre a característica interdisciplinar da CI para confirmá-la, "porque seu próprio objeto de estudo aponta para a relevância deste seu caráter". Targino (1995, p. 14) vai além e afirma que "diante dessa interdisciplinaridade irrefutável, a CI emerge como metaciência ou supraciência, no sentido de que [...] ultrapassa fronteiras rigidamente demarcadas para interagir com outras áreas". González de Gómez (2001, p. 5) diz que a orientação "interdisciplinar ou transdisciplinar" do campo se justifica pelo "caráter estratificado de informação" e pela obrigação de "articular as dimensões do objeto informacional: semânticas, sintáticas, institucionais, infraestruturais, entre outras".

González de Gómez (2001) apresenta o que se reconhece como uma situação interdisciplinar, que ocorre quando, para a resolução de um problema, é exigida a co-ocorrência de diferentes saberes. Esse seria, segundo a autora, "o momento da comunicação e do intercâmbio informacional efetivo entre áreas do conhecimento anteriormente diferenciadas", convergindo em direção a um problema comum. A situação é resultado de um acontecimento, o encontro interdisciplinar, que se constitui pelo questionamento acerca de um problema e que requer conhecimento de fatos relevantes das áreas disciplinares envolvidas e certas 'noções' conectivas, sustentadas por esses fatos relevantes. Esses encontros interdisciplinares são gerados por "processos de hibridação, translação e deslocamentos com que certos conceitos, argumentos e dados" migram entre áreas do conhecimento (RAWSKI, 1973 apud GONZÁLEZ DE GÓMEZ, 2001, p. 16). Esse tipo de associação diferenciase, portanto, da multidisciplinaridade, situação em que não há busca de interação nos níveis metodológico ou de conteúdo, ocorrendo, apenas, espaços compartilhados por vários saberes, de acordo com Kobashi; Tálamo (2003).

GONZÁLEZ DE GÓMEZ (2003a) opta por definir interdisciplinaridade como:

Geração de conhecimentos através de diferentes modalidades de interação visando à integração de conceitos, métodos, dados, ou as abordagens epistemológicas de múltiplas disciplinas em torno de uma idéia, problema, tema, ou questão em particular; $A$ interdisciplinaridade se desenvolveria dentro do campo científico, buscando a superação e reformulação das fronteiras paradigmáticas (GONZÁLEZ DE GÓMEZ, 2003, p. 6) ${ }^{10}$.

A interdisciplinaridade designa um "exercício transversal da racionalidade", que perpassa não só as fronteiras disciplinares, mas, também, as das atividades setoriais, na produção e transmissão do

\footnotetext{
${ }^{10}$ Os termos "hibridismo" e "multidisciplinaridade" são citados por González de Gómez (2003a). Segundo a autora, eles têm em comum o fato de não existir integração ou reorganização de conhecimentos, quando se efetivam em situações de interação.
} 
conhecimento científico (GONZÁLEZ DE GÓMEZ; ORRICO, 2004, p. 11). Ela emerge, atualmente, não somente como um projeto, "mas como um factum" que existe em todos os níveis da realidade dos fóruns acadêmicos, administrativos e políticos da ciência e da tecnologia e da educação. A riqueza do trabalho interdisciplinar está no esforço requerido para o "direcionamento dos olhares para um mesmo objeto por intermédio de diferentes concepções teóricas e metodológicas" (GONZÁLEZ DE GÓMEZ; ORRICO, 2004, p. 11).

Gomes (2001), na mesma linha de pensamento, define o projeto interdisciplinar como aquele que é exigido para o tratamento de objeto específico, no qual ocorrem rupturas de fronteiras disciplinares. Completa, dizendo que, em projetos dessa natureza, as disciplinas envolvidas intercambiam informações, noções, conceituações e teorias, alcançando um esquema cooperativo, a partir do qual, não apenas os sujeitos envolvidos diretamente na execução desses projetos tornam-se especialistas com múltiplas competências, mas as próprias "gramáticas" dessas disciplinas são alteradas, interferindo, também, na formação dos futuros especialistas dessas áreas [...] a ponto de fazer despontar um novo campo disciplinar (GOMES, 2001, p. 3). A autora acrescenta que uma "interdisciplinaridade efetiva" teria um escopo ampliado, sendo aquela que vai além do movimento interno de uma disciplina e que se atualiza, também, nas intervenções promovidas na realidade social que envolve a práxis que se desdobra do fazer científico (GOMES, 2001).

Sobre a constituição da equipe interdisciplinar, Dumond e Bruno (2003) dizem que a interdisciplinaridade "acaba por exigir a reunião de indivíduos com diferentes formações intelectuais", realçando, assim, a necessidade de equipes heterogêneas em sua formação para o desenvolvimento de projetos dessa natureza. Também para Orrico (2006, p.3), "o exercício interdisciplinar implica necessariamente um trabalho coordenado de equipe", com acordo prévio sobre os métodos e conceitos a serem utilizados para o estudo de um objeto sob diferentes ângulos, que resulte em enriquecimento ou modificação das disciplinas. Na mesma linha, Marteleto, em entrevista com Gustavo Freire (FREIRE; GARCIA, 2002, p. 5), afirma que "a interdisciplinaridade, a multidisciplinaridade e a transdisciplinaridade requerem real comunicação e trabalho conjunto de pesquisadores de diferentes áreas onde ocorre uma migração dos conceitos $[\ldots]$ de maneira sustentada, discutida $[\ldots] "$.

No contexto "jovem" da ciência da informação, diz Gomes (2001), são buscadas novas experiências de estruturação das disciplinas científicas por estar em uma área "fronteiriça" a outras áreas do conhecimento e, especialmente, por trabalhar problemas relacionados à informação, com alto nível de complexidade. Contudo, a interdisciplinaridade pressupõe que uma ciência se estabeleça como tal, de forma a poder dialogar científica e abertamente com outras disciplinas. $\mathrm{E}$, para tanto, segundo a autora, é necessário compor-se de um núcleo de conhecimentos, métodos de investigação e um campo experimental, para 
que sejam criados contextos de trocas de conhecimentos e de métodos com outras disciplinas. Uma ciência deve possuir definições próprias sólidas, baseadas em acordos tácitos sobre "suas bases, suas atividades e perspectivas futuras, determinando, assim, seu núcleo básico orientador das ações investigativas, a partir do qual se torna possível o diálogo com qualquer outra disciplina", e não apenas a absorção de narrativas. "O debate científico aberto entre as disciplinas é fundante da verdadeira interdisciplinaridade" (GOMES, 2001, p. 4). Também para Garcia (2002) e para Sihiral e Lourenço (2002), essa aparente dependência de teorias de outras ciências se justifica por ser a CI uma área relativamente jovem, que recebe contribuições de outras disciplinas para a construção de seu arcabouço teórico, estando, ainda, em formação. A procura por uma configuração teórica que forneça sustentação aos discursos e às práticas informacionais da área e que lhe dê uma identidade de pesquisa própria é uma busca constante entre os pesquisadores, desde o surgimento da CI (COUZINET; SILVA; MENEZES, 2007).

Smith (1992, p. 263) chega a afirmar que "há uma aparente discrepância entre o que é dito, ou seja, as muitas enumerações do caráter interdisciplinar da LIS, e o que é feito, isto é, há um "relativo isolamento da pesquisa em $\mathrm{CI}$ do ambiente de pesquisa de outras disciplinas", com poucos estudos sobre as práticas de importação e exportação com outras disciplinas. A ciência da informação precisa, segundo Gomes (2001), definir qual é o seu núcleo principal. Feito isso, a CI poderá, então, identificar quais disciplinas de fato dialogam com ela, a ponto de fazerem parte deste núcleo, discernindo-as das disciplinas nas quais a CI se apoia para a construção do seu arcabouço teórico, mas com as quais não acontece uma interação ativa de conteúdos científicos, e estariam, portanto, integrando um campo do tipo multidisciplinar com a CI. Muitos autores indicam um número grande dessas áreas visitadas pela $\mathrm{CI}$ e das quais incorpora conhecimentos, o que não as caracteriza, efetivamente, como disciplinas fronteiriças integrantes de seu núcleo principal (GOMES, 2001).

Muitas vezes, a interdisciplinaridade é confundida na CI, "com a mera incorporação de conceitos, teorias e métodos de uma disciplina por outra, ou com o esforço dos pesquisadores, que, no seu período de qualificação migram, temporariamente para 0 interior de uma determinada área", a fim de se qualificar em função da complexidade dos objetos de estudo, afirma Gomes (2001). Esse percurso, completa a autora, potencializa, sugere a necessidade de e oferece condições ao aparecimento da interdisciplinaridade, mas ela só se concretizará a partir do diálogo concreto entre as disciplinas, quando o intercâmbio ocorre em vários sentidos. Segundo Oliveira Filho (1995 apud KOBASHI; SMIT; TÁLAMO, 2001), a interdisciplinaridade da $C I$, realizada quase que exclusivamente pela assimilação de conceitos de outras áreas, tem sido chamada de eclética (ou monológica). O significado do termo eclético remete ao "uso de conceitos fora de seus respectivos esquemas conceituais e sistemas teóricos, alterando seus significados..." e 
esvaziando o discurso. Dessa forma, conceitos metodológicos passam a nomear e classificar rituais de postura, que não terão influência nas estratégias de investigação. "Os termos, vazios de significado (sem conceitos) não podem funcionar como instrumentos de reconstrução teórica ou metodológica" (OLIVEIRA FILHO, 1995 apud KOBASHI; SMIT; TÁLAMO, 2001, p. 2). O autor sugere, para evitar a interdisciplinaridade do tipo monológico ou eclético, que a institucionalização disciplinar da CI seja efetivada pela ativação da memória do campo da informação e por meio de metodologias adequadas. Assim, evita-se uma indesejável consequência desse tipo de interdisciplinaridade, que é definição circunstancial da área e não como um todo (SMIT; TÁLAMO; KOBASHI, 2004). Isso ocorre porque o significado do termo "ciência da informação", quando a área realiza apropriações de outros campos do saber, é determinado, normalmente, em função do problema investigado, que recorre à psicologia, à informática ou à administração, para tratar questões relativas a usuário, informática documentária ou administração de sistemas, de acordo com sua necessidade (SMIT; TÁLAMO; KOBASHI, 2004). Para tanto, Kobashi, Smit, Tálamo (2001) reafirmam o papel fundamental do uso de uma terminologia própria da CI, contemplando conceitos próprios e de empréstimo, estabelecendo, assim, uma linguagem autônoma da área.

Para Barreto (2002), o próprio pensar em si e a metodologia importada devem estar de acordo com as características existentes e manifestas da área da $\mathrm{CI}$, do objeto informação e todas as suas condições, características e singularidades. Deve ser explicitado como as ideias externas se inserem no mundo da CI (BARRETO, 2002). Em função da promoção de uma "verdadeira interdisciplinaridade", como diz Gomes (2001, p. 5), com enriquecimentos recíprocos, é necessário compreender o que se entende por CI e qual é o seu objeto de interesse. Smit (2002, p. 27) diz, com relação à CI: "temos mais clareza sobre as ciências com as quais nos relacionamos do que sobre a identidade da nossa própria área" (SMIT, 2002, p. 27). Essa situação, denominada por muitos interdisciplinaridade, não é suficiente para promover um novo patamar de discussões, afirma a autora.

Contribuições epistemológicas sobre as relações da CI com outras disciplinas ocorrem com pouca frequência na área da $\mathrm{CI}$, o que pode ser visto na pesquisa de Bicalho e Oliveira (2008; a pesquisa de Oliveira (2008), que analisou a produção da área sobre o tema, com o objetivo de verificar em que medida ocorre a reflexão na área, sobre suas relações disciplinares com outras áreas, por meio de uma amostra de artigos publicados em periódicos editados no Brasil. Dos 700 artigos analisados, apenas 11 (1,6\% do total) desenvolveram algum tipo de reflexão sobre os termos inter ou transdisciplinar (e variações).

Como se pode ter notado, a noção de interdisciplinaridade não está bem definida, também, no âmbito da ciência da informação. Dentro do contexto de imprecisão terminológica da área, pode ser, em alguns casos, 
até mesmo substituída pela noção de reunião ou junção de diferentes disciplinas, das quais a CI toma como seus quadros nocionais, afirmam Smit; Tálamo; Kobashi (2004). As autoras concluem que a área mantém interfaces muito próximas com diversas outras áreas do conhecimento, mas que há predomínio das "importações" sobre as contribuições da CI para outras áreas. Essa situação, já apontada em outros estudos, como os de Smith (1992) e Pinheiro (1999), reflete uma "interdisciplinaridade formal", e não uma "interdisciplinaridade real", caracterizada por empréstimos de termos de outras áreas "sem que haja uma adaptação, ou customização, dos conceitos aos propósitos da área" (SMIT; TALAMO; KOBASHI, 2004), conclusão também indicada por Barreto (2002). Marteleto, em entrevista para Freire e Garcia (2002), vai além e diz que a área da CI se diz interdisciplinar, mas pouco prática de interdisciplinaridade, entendendo-a como a "simples citação a conceitos de outra área".

Bicalho e Oliveira (2008) apontam para a escassez de trabalhos que busquem uma reflexão sobre o termo interdisciplinaridade, amplamente aceito como característica da CI, mas cujo significado e implicações no âmbito das práticas de investigação da área não parecem ser preocupações significativas. Em pesquisa que utilizou como fonte os projetos financiados pelo CNPq, Oliveira (1998, p. 47) conclui que "a área não tem vivenciado situações interdisciplinares. Algumas atividades de pesquisa têm conseguido apenas algum tipo de multidisciplinaridade, [...] sem tentativa de síntese". Para minimizar este problema, a autora afirma que é necessário "buscar contribuição de outras áreas, mas de forma consciente e compromissada, sem diluir-se nessas novas formas de intercâmbio" (OLIVEIRA, 1998, p. 47). A indução a pesquisas interdisciplinares, entre outras ações, segundo a mesma autora (2001), poderia contribuir para a "constituição de conhecimentos [...], que resultem em novas descrições da área e possibilitem o uso de outras alternativas metodológicas para a ciência da informação".

Para González de Gómez (2003), a CI busca facilitar a articulação de seu ponto de vista e seu campo de visão, por meio de relações com saberes como os estudos da política, da comunicação, epistemologia social, estudos sociais da ciência, estudos econômicos, da estética e das artes e, por outro lado, compartilha seu campo de visão (embora sob outro ponto de vista) com a biblioteconomia, a arquivologia e a museologia. E, para contextualizar a informação como seu objeto de pesquisa, a área precisa se aproximar de outras disciplinas, afirma a pesquisadora. Assim, a contextualização da dimensão narrativa da informação se aproximaria dos estudos da linguística, da história, da antropologia e das teorias semiótica e do discurso; sua dimensão regulatória e estruturante far-se-ia por aproximação com administração, sociologia e direito; a dimensão econômica e tecnológica com a ciência da computação e as telecomunicações. Esse contexto de interação seria capaz de estabelecer um "intercâmbio denso tanto entre os saberes e sujeitos que constroem o ponto de vista, quanto com os que enriquecem o 
campo de visão", constituindo um "encontro transdisciplinar" (GONZÁLEZ DE GÓMEZ , 2003, p. 42).

Muitas disciplinas são identificadas como parte das interações da CI. As relações interdisciplinares com a ciência da computação e a biblioteconomia são, para Pinheiro (2005, p. 17), "inegavelmente, fonte de exercício interdisciplinar", devido à aplicação de computadores, à recuperação da informação e problemas similares, no caso da computação e devido à função social da área que é comum à CI e à Biblioteconomia, aspecto que fortalece a relação entre ambas, conforme afirma Saracevic (1992 apud PINHEIRO, 2006). Nesse artigo, a pesquisadora confirma a existência de diferentes níveis de interação com outras disciplinas, como sendo a mais forte, isto é, a que apresentou maior número de ocorrências em sua pesquisa, a ciência da computação, seguida da biblioteconomia e da administração. Em terceiro lugar surgem linguística e economia, seguidas de arquivologia, comunicação, direito, estatística, filosofia, história da ciência, matemática, museologia e sociologia da ciência. $E$, finalmente, foram identificadas interações mais fracas, com as disciplinas de ciência política, educação, ética, epistemologia e filosofia da ciência. Esses resultados, segundo Pinheiro (2006), podem refletir alguns fatores próprios da evolução da CI. Em relação à biblioteconomia, considera que seja uma das áreas mais citadas e reconhecidas nas pesquisas na ciência da informação, desde o surgimento da CI. Com a ciência da computação, ressalta o caráter instrumental desse campo, o que nem sempre efetiva uma contribuição interdisciplinar, de fato, segundo a autora. Com relação a forte interação com a administração, a autora afirma ter papel importante a gestão do conhecimento e a inteligência competitiva, devido ao aumento da competitividade nas empresas e no setor produtivo, em virtude da globalização de mercado e de capital. A presença da relação com a economia se deve principalmente à gestão da informação e à economia da informação e, com a lingüística, à sua interface com os sistemas de recuperação da informação, representação da informação e processamento automático de linguagem. A autora chama a atenção, também, para o fato de que a psicologia, com forte interação com a CI nas primeiras décadas, apareça somente no domínio de necessidades e usos de informação. Essas mudanças, afirma Pinheiro (2006), constituem resultado das transformações oriundas das relações interdisciplinares que a área promove e sofre, quando interage com outras disciplinas, o que vai modificando o seu "território".

Moreira e Moura (2006) afirmam que a CI se caracteriza por estudos de cunho multidisciplinar e interdisciplinar, com representação temática híbrida, resultante das especificidades do campo e dos conceitos vindos das fronteiras de seu domínio. Eles identificam uma relação de primeiro nível (em círculo), que a CI (juntamente com a biblioteconomia) estabelece com suas áreas limítrofes mais próximas, a saber: administração, arquivologia, ciências cognitivas, ciências da computação, economia, educação, linguística, museologia e sociologia, as quais se 
seguem a filosofia, as ciências políticas, a história e o direito, que se relacionam com as disciplinas centrais e com as do primeiro círculo.

Os resultados da pesquisa completa, citada anteriormente (BICALHO, 2009), indicam que as disciplinas com as quais a CI interage são muitas. O estudo aprofundado dos 158 artigos publicados em periódicos da área, desenvolvidos em interação com outras, deu origem a mapa demonstrativo da frequência em que ocorrem. Distribuindo-se as disciplinas por percentuais de interação, em dez conjuntos, obteve-se: $1^{\circ}$ ) biblioteconomia $(29 \%) ; 2^{\circ}$ ) administração/engenharia de produção $\left.(25 \%) ; 3^{\circ}\right)$ epistemologia $(7 \%)$; muito próxima, em $4^{\circ}$. lugar: sociologia/antropologia $(6,5 \%) ; \quad$ em $\left.5^{\circ}\right)$ educação e ciência da computação $(4,5 \%)$; em $\left.6^{\circ}\right)$, com $3 \%$ dos artigos, estão: estatística e semiótica/semiologia; artes $(2,5 \%)$ está em $7^{\circ}$ ) lugar; no $8^{\circ}$ ) grupo, com 2\% dos artigos, estão: economia, filosofia e linguística/terminologia; $9^{\circ}$ ) arquivologia, ciências cognitivas, comunicação social e sociologia da ciência, com 1,5\% artigos; e na $10^{\mathrm{a}}$ ) estão as áreas de ciência política, história, história da ciência, museologia e psicologia, com 0,5\% artigo em cada.

\section{A questão da transdisciplinaridade na CI}

Tratando especificamente da abordagem transdisciplinar na CI, algumas referências ao termo ou a esse tipo de pesquisa são encontradas. Inicia-se com recomendação de Wersig e Windel (1993) de que a CI deva entretecer conceitos de forma "evolucionária, sinóptica e transdisciplinar", para que consiga navegar conceitualmente "dentro de uma teoria sob a forma pós-moderna, numa rede centrada no conhecimento, sob a ótica do problema do uso do conhecimento em condições pós-modernas de informatização" (WERSIG; WINDEL, 1993 apud PINHEIRO, 1997, p.160). González de Gómez (2003a) informa que a transdisciplinaridade tem origem na associação de novas demandas éticas e políticas, à busca de inovações epistemológicas. A autora define transdisciplinaridade sob três perspectivas:

a) Geração de novos conhecimentos integrados por novos axiomas (ou meta-regras), comuns a um conjunto de disciplinas e saberes nãodisciplinares;

b) Junção de um programa de pesquisa e de um programa de ação, em torno de questões ou problemas contextualizados, nos quais processos de aprendizagem e descoberta são organizados por uma matriz intersubjetiva transdisciplinar, composta por uma rede de sujeitos individuais e coletivos, implicados naquela junção por objetivos comuns e por alguma forma de aliança ou parceria;

c) Geração de estruturas de compartilhamento que transgredirem as fronteiras e estruturas disciplinares, organizacionais e de setores de atividade, mantendo as condições, demandas e expectativas do 
conhecimento científico - além da singularidade de um caso ou da solução de um problema pontual (GONZÁLEZ DE GÓMEZ, 2003a, p. 6).

A ocorrência de "formas de articulação e reunião de saberes e práticas, que respondem melhor ao conceito de transdisciplinares" é justificado, quando houver "demanda de conhecimentos científicos e tecnológicos a serem utilizados na resolução de problemas que identificam "zonas obscuras de ignorância", no contexto das diversas atividades sociais, como a indústria ou a saúde coletiva" (GONZÁLEZ de GÓMEZ, 2003, p. 40). Novas estruturas de interação entre disciplinas foram favorecidas no pós-guerra, entre as quais a autora cita os programas de pesquisa em meio ambiente, estudos culturais, estudos da mulher, entre outros.

Ao abordar a questão da informação na sociedade contemporânea, Kobashi, Yumiko e Tálamo (2003), relacionam os desafios da ciência da informação, em que incluem o estabelecimento de relações inter e transdisciplinares, sem o risco de se dissolver nas outras disciplinas. As autoras se posicionam sobre o que entendem pelo termo, com base em Edgar Morin e em suas reflexões sobre a teoria da complexidade. Dumond; Bruno (2003) relacionam o termo transdisciplinaridade à prática de socialização da informação, chamada de "intertematicidade".

Alguns artigos publicados que mencionam as interações disciplinares da CI não chegam a discutir o significado ou implicações de uso do termo "transdisciplinaridade", o que, em princípio, deve ser compreendido ou deduzido pelos leitores. Neves (2006) diz, na conclusão de suas reflexões sobre CI e cognição humana, que "os estudos focalizados [...] dão uma pequena demonstração das possibilidades que se abrem diante [...] de estudos transdisciplinares" (NEVES, 2006, p. 43). Marciano e LimaMarques (2006), discorrendo sobre segurança da informação sob o enfoque social, afirmam que a transdisciplinaridade é parte do caráter da $\mathrm{CI}$, o que se verifica pela teoria geral dos sistemas ou pelas ciências cognitivas: "A CI [...] ao ressaltar o próprio caráter transdisciplinar e o seu relacionamento com a comunicação, [...] analisa os aspectos da comunicação organizacional ora pela óptica da teoria geral dos sistemas [...], ora pela óptica dos processos cognitivos envolvidos na geração e na externalização desta comunicação" (MARCIANO; LIMA-MARQUES, 2006, p. 90).

Alguns usos dos termos interdisciplinar por transdisciplinar e viceversa são, também, encontrados. Isto pode ser evidenciado por meio da leitura dos artigos em que os termos são usados com sentidos equivalentes ou pouco distintos, como em Freire (2004) e González de Gómez (2001; 2003a). Esses usos podem estar associados às novidades proporcionadas pelo surgimento de termos mais recentes ou às modificações associadas aos seus conceitos. 


\section{Considerações finais}

A pesquisa mostrou que ainda há diferentes concepções, definições e classificações atribuídas às abordagens multi, inter e transdisciplinar. A distinção entre elas, na prática da pesquisa, pode ser tarefa difícil, quando se aproxima dos limites, entretanto, um conjunto de características compõe um quadro conceitual, que pode permitir a identificação de cada uma. Apesar dessas dificuldades, refletir sobre essas abordagens só faz sentido se forem relacionadas a uma forma de pensar as disciplinas em interação, manifestada na investigação científica, como forma de consolidar suas bases teórico-conceituais.

No entanto, a questão das relações frequentes e profícuas, na maioria das vezes, entre Ciência da Informação e outras disciplinas, não tem sido tratada no âmbito da área com a devida profundidade que o tema exige, em se tratando de pesquisa científica. São muitos os fatores que favorecem a prática da multi, da inter e mesmo da transdisciplinaridade, no âmbito da CI. Os estudos informacionais são fontes inesgotáveis de trocas de conhecimentos com diferentes áreas, com as quais é necessário dialogar aberta e reciprocamente. Contudo, é importante para qualquer área, especialmente para a CI, ter clareza sobre o fato de que ser uma ciência interdisciplinar pressupõe ir além da formação de seus pesquisadores ou de sua composição inicial, a partir de várias áreas. Até mesmo porque, se uma nova área é criada a partir das zonas fronteiriças de interseção com outras, ela passa a constituir uma disciplina, com todas as condições que a caracterizam como tal, sem que seja, necessariamente, interdisciplinar. A prática de pesquisa entre disciplinas exige mais que a incorporação ou soma de informações, noções, conceituações e teorias. Para ocorrer a interação, em nível adequado, é necessário buscar a cooperação entre os envolvidos naquela investigação, sabendo-se que tipo de abordagem está sendo exigida naquela situação, se multi, inter ou transdisciplinar. Para tanto, os termos devem ser conhecidos e seus significados minimamente compreendidos por toda a comunidade. Além disso, para que as relações ocorram, é necessário, sobretudo, que as disciplinas envolvidas tenham conhecimento de seu alcance e de seus próprios limites, de forma a contribuir e se enriquecer ao mesmo tempo.

Finalizando, pode-se afirmar que a reflexão sobre os termos inter, trans e mesmo multidisciplinar está pouco desenvolvida para uma ciência que se diz interdisciplinar. Afinal, espera-se que esta pesquisa possa subsidiar e ampliar as discussões na área sobre as características dos vários tipos de interações entre disciplinas nas ciências, possibilitando uma avaliação do significado que cada termo carrega efetivamente, em nível teórico, a fim de serem utilizados adequadamente na prática de pesquisa. 


\section{Referências}

BARRETO, A. A. O tempo e o espaço da ciência da informação. Transinformação, v. 14, n. 1, p. 17-24, jan./jun. 2002.

BERGER, G. Conditions d'une problèmatique de I'interdisciplinarité. In: CERI (Ed). L'Interdisciplinarité: problèmes $d$ 'enseignement et de recherche dans les Université. Paris: UNESCO/OCDE, 1972. p. 21-24 apud POMBO, O. Contribuição para um vocabulário sobre interdisciplinaridade. In: POMBO, O.; GUIMARÃES, H.; LEVY, T. Interdisciplinaridade: reflexão e experiência. 2 ed. Lisboa: Texto, 1994.

BICALHO, L. M. As relações interdisciplinares refletidas na literatura brasileira da Ciência da Informação. Belo Horizonte: UFMG, 2009. $267 f$. Tese (Doutorado em Ciência da Informação) - Programa de PósGraduação em Ciência da Informação, Escola de Ciência da Informação, Universidade Federal de Minas Gerais, Belo Horizonte, 2009.

BICALHO, L. M.; OLIVEIRA, M. As relações interdisciplinares e a CI. In: ENANCIB, 9., 2008. Anais... São Paulo: USP, 2008.

BOISOT, M. Discipline and Interdisciplinarity. In: APOSTEL, L. Interdisciplinarity: problems of teaching and research in universities. Paris: OCDE, 1972. p. 89-97 apud KLEIN, J. T. Interdisciplinarity: history, theory, and practice. Detroit, Michigan: Wayne State University Press, 1990.

BORKO, H. Information science: what is it? American Documentation, v. 19, n. 1, p. 3-5, jan. 1968.

BRANDÃO, C. A. L. Transdisciplinarity, yesterday and today. SIGGRAPH 2007, San Diego/EUA, p. 334-337, 2007.

COUZINET, V.; SILVA, E. L. S.; MENEZES, E. M. A ciência da informação na França e no Brasil. Datagramazero, v. 8, n. 6, dez. 2007. Disponível em: <http://www.datagramazero.org.br/dez07/Art 03.htm>. Acesso em: 17 dez. 2007.

DELATTRE, P. Investigações interdisciplinares: objetivos e dificuldades. In: POMBO, O.; GUIMARAES, H. M.; LEVY, T. Interdisciplinaridade: antologia. Porto/PT: Campo das Letras, 2006. p. 279-299.

DIAS, E. W. Biblioteconomia e ciência da informação: natureza e relações. Perspectivas em Ciência da Informação, Belo Horizonte, v. 5, n. especial, p. $67-80,2000$.

DOMINGUES, I. et al. Um novo olhar sobre o conhecimento: a criação do Instituto de Estudos Avançados Transdisciplinares e os novos paradigmas. In: DOMINGUES, I. (Org.) Conhecimento e transdisciplinaridade. Belo Horizonte: Editora UFMG, 2001. p. 13-27.(Coleção IEAT).

DUMOND, L. M. M.; BRUNO, P. P.C. CI e oportunidade de diálogo intertemático: onde nem tudo é relativo e nem (absolutamente) racional. Perspectivas em Ciência da Informação, v. 8, n. 1, p. 28-39, 2003. 
FREIRE, I. M. O olhar da consciência possível sobre o campo científico. Ciência da Informação, v. 32, n. 1, p. 50-59, jan./abr. 2003.

A rede de projetos do núcleo temático da seca da UFRN como possibilidade de socialização da informação. Informação e sociedade, v. 14, n. 2, p. 1-11, 2004.

FREIRE, G. H.; GARCIA, J. C. R. Avaliação científica: a visão do pesquisador. Informação \& Sociedade, v. 12, n. 2, p. 1-11, 2002.

GARCIA, J. C. R. Conferências do Geórgia Institute of Technology e a ciência da informação: "de volta para o futuro". Informação \& Sociedade, v. 12, n. 1, p. 54-66, 2002.

GOMES, H. F. Interdisciplinaridade e Ciência da Informação: de característica a critério delineador de seu núcleo principal. Datagramazero, v. 2, n. 4, 2001. Disponível em: <http://www.dgz.org.br/ago01/F_I_art.htm>. Acesso em: 17 maio 2009.

GONZÁLEZ DE GÓMEZ, M. N. Os vínculos e os conhecimentos: pensando o sujeito da pesquisa trans-disciplinar. In: ENANCIB, 5., 2003. Anais... Belo Horizonte: Escola de Ciência da Informação/UFMG, $2003 a$.

- Escopo e abrangência da ciência da informação e a pósgraduação na área: anotações para uma reflexão. Transinformação, v. 15, n. 1, p. 31-43, jan./abr. 2003.

Para uma reflexão epistemológica acerca da ciência da Informação. Perspect. Cienc. Inf., Belo Horizonte, v. 6, n. 1, p. 5-18, jan/jun. 2001.

GONZÁLEZ DE GÓMEZ, M. N.; ORRICO, E. G. D. As políticas institucionais das configurações interdisciplinares dos conhecimentos: repercussões nas políticas de informação e nas práticas de avaliação. Datagramazero, v. 5, n. 6, dez. 2004. Disponível em: <http://www.dgz.org.br/dez04/F_I_art.htm>. Acesso em: 17 maio 2009.

GUSDORF, G. Conhecimento interdisciplinar. In: POMBO, O.; GUIMARAES, H. M.; LEVY, T. Interdisciplinaridade: antologia. Porto/PT: Campo das Letras, 2006. p.37-58.

Reflexions sur l'interdisciplinarité. Bulletin de Psychologie, v. 43, n. 397, p. 847-868, 1990 apud POMBO, O. Contribuição para um vocabulário sobre interdisciplinaridade. In: POMBO, O.; GUIMARÃES, H.; LEVY, T. Interdisciplinaridade: reflexão e experiência. 2 ed. Lisboa: Texto, 1994.

HECKHAUSEN, Heinz. Discipline and Interdisciplinarity. In: Interdisciplinarity: problems of teaching and research in universities, Paris: Organization for Economic Cooperation and Development, 1972, p. 83-89 apud KLEIN, Julie Thompson. Interdisciplinarity: history, theory, and practice. Detroit, Michigan: Wayne State University Press, 1990 apud POMBO, O. Contribuição para um vocabulário sobre interdisciplinaridade. 
In: POMBO, O.; GUIMARÃES, H.; LEVY, T. Interdisciplinaridade: reflexão e experiência. 2 ed. rev. aum., Lisboa: Texto, 1994

HECKHAUSEN, $H$. Disciplina ou interdisciplinaridade. In: POMBO, O; GUIMARAES, H. M.; LEVY, T. Interdisciplinaridade: antologia. Porto/PT: Campo das Letras, 2006.

HUERKAMP, C. et al. Criteria of interdisciplinarity. In: CENTER FOR INTERDISCIPLINARY RESEARCH. The University of Bielefeld: annual Report 1978 and Supplement 1979-1981. p. 23-24 apud KLEIN, J. T. Interdisciplinarity: history, theory, and practice. Detroit, Michigan: Wayne State University Press, 1990.

JAPIASSU, H. Interdisciplinaridade e patologia do saber. Rio de Janeiro: Imago, 1976.

JAPIASSU, H.; MARCONDES, D. Dicionário básico de filosofia. Rio de Janeiro: Zahar, 1991.

KLEIN, J. T.Unity of knowledge and transdisciplinarity: contexts of definition, theory and the new discourse of problem solving. 2002. In: Encyclopedia of Life Support Systems (EOLSS, UK). Disponível em: <http://www.mines.edu/newdirections/essay2.htm>. Acesso em: 9 dez. 2003 apud SOMMERMAN, A. Inter ou transdisciplinaridade: da fragmentação disciplinar ao novo diálogo entre os saberes. São Paulo: Paulus, 2006.

KLEIN, J. T. Interdisciplinarity: history, theory, and practice. Detroit, Michigan: Wayne State University Press, 1990.

KOBASHI, N. Y.; TÁLAMO, M. F. G.M. Informação: fenômeno e objeto de estudo da sociedade contemporânea. Transinformação, v. 15, n. especial, p. 7-21, set./dez. 2003.

KOBASHI, N. Y. et al. A função da terminologia na construção do objeto da ciência da informação. Datagramazero , v. 2, n. 2, 2001.

LE COADIC, Y-F. A ciência da informação. Brasília: Briquet de Lemos, 1996.

MARCIANO, J. L.; LIMA-MARQUES, M. O enfoque social da segurança da informação. Ciência da Informação, v. 35, n. 3, p. 89-98, set./dez. 2006.

MERTA, A. Informatics as a branch of science. In: INTERNATIONAL FEDERATION FOR DOCUMENTATION (FID/RI). Study Committee Research o Theoretical Basis of Information. On theoretical problems of informatics, Moscow, ALL-Union for Scientific and Technical Information, 1969 (FID 435), p.38-39 apud PINHEIRO, L. V. R. A ciência da informação entre sombra e luz: domínio epistemológico e campo interdisciplinar. 1997. Tese (Doutorado em Comunicação) - Escola de Comunicação, UFRJ.

MOREIRA, M. P.; MOURA, M. A. Construindo tesauros a partir de tesauros existentes: a experiência do TCI - Tesauro em CI". Datagramazero, v. 7, n. 4, ago. 2006. 
MORIN, E. Ciência com consciência. 10 ed. Rio de Janeiro: Bertrand Brasil, 2007.

Piaget, 2003.

Introdução ao pensamento complexo. 4 ed. Lisboa: Instituto

A articulação dos saberes. In: MORIN, E.; ALMEIDA, M. C.; CARVALHO, E. A. (Orgs). Educação e complexidade: os sete saberes e outros ensaios. São Paulo: Cortez, 2002

- O pensamento complexo, um pensamento que pensa. In: MORIN, Edgar; LE MOIGNE, Jean-Louis. A inteligência da complexidade. 2 ed. São Paulo: Peirópolis, 2000. p.197-214.

Ciência com consciência. Barcelona: Anthropos, 1982 apud SOLANA-RUIZ, J. L. Sobre el concepto de complejidad: de lo simplificable a la fraternidad amante. Cronos, v. 2, n. 2, p. 31-39, 2001.

NEVES, D. A. Ciência da informação e cognição humana: uma abordagem do processamento da informação. Ci. Inf., v. 35, n. 1, p. 39-44, 2006.

NICOLESCU, B. Transdisciplinarity as methodologial framework for going beyond the science-religion debate. In: Transdisciplinary and the unity of knowledge: beyond the science and the religious dialogue. Philadelphia/USA, 2-6 June, 2007. Disponível em: <http://www.metanexus.net/ conference2007/papers/\#227>. Acesso em: 02 maio 2008.

2001.

O manifesto da transdisciplinaridade. 2 ed. São Paulo: Triom,

NICOLESCU, Basarab et al. Educação e transdisciplinaridade. Brasília: UNESCO, 2000 (Edições UNESCO).

OLIVEIRA, Marlene. A investigação científica na ciência da informação: análise da pesquisa financiada pelo $\mathrm{CNPq}$ - Tese de Doutorado. Brasília: IBICT, 1998

OLIVEIRA, M. A pesquisa científica na ciência da informação: análise da pesquisa financiada pelo CNPq. Perspectivas em ciência da informação, v. 6, n. 1, p. 143-156, 2001.

OLIVEIRA FILHO, J. J. Patologias e regras metodológicas. Estudos Avançados, São Paulo, v. 9, p. 263-268, jan./abr. 1995 apud KOBASHI, N. Y.; SMIT, J. W.; TÁLAMO, M. F. G.M. A função da terminologia na construção do objeto da ciência da informação. Datagramazero , v. 2, n. 2, 2001. Disponível em: <http.//www.dgz.org.br>. Acesso em: 02 maio 2008.

ORRICO, E. G. D. As metáforas na interdisciplinaridade: uma proposta possível? In: ENANCIB, 7., 2006, Marília. Anais... UNESP: Marília/SP, 2006. 
ORRICO, E. G. D. Interdisciplinaridade: ciência da informação \& linguística. In: PINHEIRO, L. V. R. Ciência da informação, ciências sociais e interdisciplinaridade. Brasília; Rio de Janeiro: IBICT, 1999.

PIAGET, J. Epistemologie des relations interdisciplinaires. In: CERI (Ed.). L'interdisciplinarité: problèmes d'enseignement et de recherche dans les Universités. Paris: UNESCO/OCDE, 1972. p. 131-144 apud POMBO, 0. Contribuição para um vocabulário sobre interdisciplinaridade. In: POMBO, O.; GUIMARÃES, H.; LEVY, T. Interdisciplinaridade: reflexão e experiência. 2 ed. rev. aum. Lisboa: Texto, 1994.

PINHEIRO, L. V. R. Ciência da informação: desdobramentos disciplinares, interdisciplinaridade e transdisciplinaridade. Disponível em: <http://www.uff.br/ppgci/editais/ lenavanialeituras.pdf>. Acesso em: 23 fev.2006.

- Processo evolutivo e tendências contemporâneas da ciência da informação. Informação e sociedade - estudos, v.15, n.1, 2005.

Campo interdisciplinar da ciência da informação: fronteiras remotas e recentes. In: PINHEIRO, L. V. R. (Org.). Ciência da informação, ciências sociais e interdisciplinaridade. Brasília/Rio de Janeiro: IBICT/DDI/DEP, 1999. p. 155-182.

Campo interdisciplinar da ciência da informação: fronteiras remotas e recentes. Investigación Bibliotecnológica, México, v. 12, n. 25, p. 132-163, 1998.

A ciência da informação entre sombra e luz: domínio epistemológico e campo interdisciplinar. 1997. Tese (Doutorado em Comunicação) - Escola de Comunicação, UFRJ, 1007.

PINHEIRO, L. V. R. ; LOUREIRO, J. M. M. Traçados e limites da ciência da informação. Ciência da Informação, Brasília, v. 24, n. 1, p. 33-42, jan./abr. 1995.

POMBO, O. Epistemologia da interdisciplinaridade. In: POMBO, 0. Interdisciplinaridade, humanismo, universidade. Porto: Campo das Letras, 2004. Disponível em: <http://www.educ.fc.ul.pt/docentes/opombo/investigacao/pontofinal.pdf> . Acesso em: 23 fev. 2006.

POMBO, O.; GUIMARÃES, H.; LEVY, T. Interdisciplinaridade: reflexão e experiência. 2 ed. rev. aum. Lisboa: Texto, 1994.

RAWSKI, C. Towards a theory of librarianship: papers in honor of Jesse $\mathrm{H}$. Shera. New Jersey: Scarecrow, 1973 apud GONZÁLEZ DE GÓMES, M. N. Para uma reflexão epistemológica acerca da ciência da Informação. Perspect. cienc. inf., Belo Horizonte, v. 6, n. 1, p. 5-18, jan/jun. 2001.

SARACEVIC, T. Information Science: origin, evolution and relations. In: VAKKARI, P.; CRONIN, B. (Eds). Conceptions of library and information science; historical, empirical and theoretical perspectives. In: THE INTERNATIONAL CONFERENCE FOR THE CELEBRATION OF 20TH 
ANNIVERSARY OF THE DEPARTMENT OF INFORMATION STUDIES OF UNIVERSITY OF TAMPERE, 1991. Proceedings... Finland; London; Los Angeles: Taylor Graham, 1992. p. 5-27.

Ciência da informação: origem, evolução, relações. Perspectivas em ciência da informação, Belo Horizonte, v. 1, n. 1, p. 41-62, jan./jun. 1996.

SIHIRAL, A. B.; LOURENÇO, C. A. Informação e conhecimento: aspectos filosóficos e informacionais. Informação e Sociedade - Estudos, v. 12, n. $1,2002$.

SMIT, J. W.; TÁLAMO, M. F.; KOBASHI, N. A determinação do campo científico da ciência da informação: uma abordagem terminológica. Datagramazero, v. 5, n. 1, fev. 2004.

SMIT, J. W. A pesquisa na área de ciência da informação. Transinformação, v. 14, n. 1, p. 25-28, jan./jun. 2002.

SMITH, L. Interdisciplinarity: approaches to understanding library and information Science as an interdisciplinary field. In: VAKKARI, P.; CRONIN, B. (Eds). Conceptions of Library and Information Science; historical, empirical and theoretical perspectives. In: THE INTERNATIONAL CONFERENCE FOR THE CELEBRATION OF 20TH ANNIVERSARY OF THE DEPARTMENT OF INFORMATION STUDIES OF UNIVERSITY OF TAMPERE, 1991. Proceedings... Finland; London; LoS Angeles: Taylor Graham, 1992. p. 253-267.

SOMMERMAN, A. Inter ou transdisciplinaridade: da fragmentação disciplinar ao novo diálogo entre os saberes. São Paulo: Paulus, 2006 .

Complexidade e transdisciplinaridade. In: ENCONTRO BRASILEIRO DE ESTUDOS DA COMPLEXIDADE, 2005. Anais... Curitiba: Pontifícia Universidade Católica do Paraná, 2005.

TARGINO, M. G. A interdisciplinaridade da ciência da informação como área de pesquisa. Informação e Sociedade, Estudos: João Pessoa, v. 5, n. 1, p. 12-17, jan./dez. 1995.

VAKKARI, P.; CRONIN, B. (Eds). Conceptions of Library and Information Science; historical, empirical and theoretical perspectives. In: THE INTERNATIONAL CONFERENCE FOR THE CELEBRATION OF 20TH ANNIVERSARY OF THE DEPARTMENT OF INFORMATION STUDIES OF UNIVERSITY OF TAMPERE, 1991. Proceedings... Finland; London; Los Angeles: Taylor Graham, 1992.

WERSIG, G.; NEVELING, U. The phenomena of interest to information science. Information Scientist, n. 9, p. 127-140, 1975 apud FREIRE, I. M. O olhar da consciência possível sobre o campo científico. Ciência da Informação, v. 32, n. 1, p. 50-59, jan./abr. 2003.

WERSIG, G.; WINDEL, G. Information science needs a theory of "information actions", Social Science Information Studies, v. 5, p. 11-23, 1993 apud PINHEIRO, L. V. R. A ciência da informação entre sombra e 
luz: domínio epistemológico e campo interdisciplinar. 1997. Tese (Doutorado em Comunicação) - Escola de Comunicação, UFRJ, 1997. 